\title{
Embodied Cognition and Enlightenment to Micro- video Design in College English Teaching
}

\author{
Xiaowen Zhou \\ Department of Foreign Languages \\ Northeast Dianli University \\ Jilin, China
}

\author{
Zhiyuan Li \\ Department of Foreign Languages \\ Northeast Dianli University \\ Jilin, China
}

\begin{abstract}
Embodied cognition argues that body plays a vital role in cognition and in language acquisition as well. Thus due attention should be paid to the "embodied" cognitive feature in students when teachers conduct instructional design and educational practice. The focus on situatedness of teaching and experiencing of learning will definitely enhance learning ability and teaching effectiveness.
\end{abstract}

Keywords-embodied cognition; micro-video; college English teaching; instructional design

\section{INTRODUCTION}

From 1980s, it came to their awareness for more and more researchers that body is indispensable in cognitive process, and then the first-generation cognitive science of "away from body" transformed to the second-generation cognitive science of "embodied". Language acquisition, as one form of cognitive processes, inevitably has certain connection with "embodiedment". It's required that in language teaching teachers should understand the core of embodied cognition theory and are equipped with the teaching notions of "bodymind" unity, then the effectiveness of teaching, and learning ability as well, would consequently be improved.

\section{EMBODIED COGNITION}

At first, the study of embodied cognition is only a kind of philosophical thinking. Heidegger, Merleau-Ponty, Dewey and Vygotsky have innovative ideas towards cognitive process, and contribute to the emergence of embodied philosophy. Embodied philosophy, which has three basic rules-- the embodies mind, the cognitive unconsciousness, and metaphorical thought, has become the theoretical basis of embodied cognition, and the watershed between the firstgeneration cognitive science and the second-generation cognitive science.

Then, the study of embodied cognition has extended to the experimental study of cognitive psychology. The embodied cognition approach in cognitive psychology is featured as the emphasis it places on the role of the body plays in an organism's cognitive process, the central meanings of which claim:

- $\quad$ steps in a cognitive process might merge from the physical attributes of the body;

*The Project Supported by 2015 Jilin Provincial Education Science Program of China, Grant No. GH150299.
- it tries to account for the content of cognition by appeal to the nature of the body;

- cognitive processes or states might be extended into the environment in which the cognition takes place. (H.S. Ye, 2010)

According to M.L. Anderson (2003), embodied cognition view argues "Cognition is a high embodied and situated action." The stance has emphasized body's interaction with the environment, which provides a systematic description of the interactions of mind-body-world. As M. Wilson (2002) claims, "There is a growing commitment to the idea that the mind must be understood in the context of its relationship to a physical body that interacts with the world." In his "Six views of embodied cognition", M. Wilson distinguishes and evaluates six claims on embodied cognition:

- $\quad$ cognition is situated;

- cognition is time-pressured;

- we off-load cognitive work onto the environment;

- the environment is part of the cognitive system;

- cognition is for action;

- off-line cognition is body based.

Embodied cognition, a cognitive style after the rising of the second generation of cognitive science, is enjoying increasingly broad support, which brings about great value, expands interdisciplinary research and provides researchers with a great deal of inspiration on the studies of cognitive theory, cognitive linguistics, applied linguistics or English teaching for language cognition. (X.W. Xu, 2010) Xu suggests that the findings of cognitive science of language show that an individual's internal performance can play a very important and simulatory role in helping him with his comprehension, conception and expression of language.

Cognitive linguistics, proposed by Lakoff \& Johnson, hold that human concepts originate form the recognition of self and space (including location, direction, movement, etc.), or the basis of which conceptual system has been gradually formed by means of metaphor and some other basic cognitive strategies. (Y. Wang, 2004) Wang tries to explain, from the viewpoint of embodied philosophy and cognitive linguistics, the motivation of words and morphology, the formation of 
syntax and context, and its application to Experiencing English teaching.

The paper "Educational significance and latent value of embodied cognition" written by Y.Y. Li and Y.H. Mo (2011) argues that "away from body -- embodied" is a continuum, which needs to be integrated. On this basis, combined with "knowledge-language metaphor", "skills-body spatiality" and "emotion-body situation" in three dimension, the paper explores the significance and value of embodied cognition for education. J. Wang \& W.D. Chen (2012) suggests embodied cognition has deeper meaning in helping us understand learning, clear the starting point of education practice, and it also provides a feasible epistemological base of more inclusive theory-grounded instructional design. Meanwhile, embodied cognition shows the significance of enlightenment in developing instructional design paralleled with instructional activities, in designing "cognition system" environment merging of biological and electronic, and in facilitating learning.

\section{MICRO-VIDEO}

Nowadays, education technology has gone rapid development with the help of information technology, Big Data, digital technology, and E-learning. Some researchers, such as Z. T. Zhu (2012), K. K. He (2014), and T.S. Hu (2011), conduct a series of studies focused on digital education, education informatization, micro-class design, and construction of multimedia course-ware. Against this background, videos as teaching resources are considered as a vital means for information dissemination and sharing. Especially in recent years, more call for open, diverse, and sharing learning resources are emerged, therefore, open learning video resources has been brought about positive influence on education. Micro-video learning course, as a form of curriculum design in fragmented learning age, could better meet learners' need, and thus become the focus of education (M. Wang, 2013).

There is no unified definition for micro-video now, while the author tends to prescribe it as the video used in class full of teaching significance, ranged from 5 minutes to 10 minutes. The micro-video resources should consist of meaningful and helpful knowledge module, and to meet the needs of particular courses. It also should be suitable for teaching contents, course nature and capacity. The time range is from 5 minutes to 10 minutes because the video shorter than 5 minutes may not be long enough for students to fully understand the presupposited language context. Meanwhile, it is acknowledged that the cognitive process within 10 minute would be quite effective, and beyond the time range, it seems the efficiency of cognition would be weakened gradually, and the effectiveness of teaching in the class could also be reduced.

The characteristics of micro-video as learning resources are short, precise, situated and subject-prominent. Micro-video is situated since it is usually made under situated-class circumstance, that is, micro-video is closely associated with specific subjects in learning activities, especially experiencing learning of certain topics. At the same time, more emphasis will be laid on information sharing and interactivity between students-context, and students-teachers as well. It is also convenient and easy-made, even students could make the video by themselves with the help of their mobile phones. Or the videos, such as, English films, TV programs (TV series, speeches, news reports and even MTV), and Online courses (for example, MOOC) could be the raw materials that teachers and students could adopt and make certain adaption to certain topics in order to satisfy their needs in teaching and learning.

Consequently, students have access to language resources used under almost "real" circumstances. Besides, with the help of diverse materials of situated topics, vivid images, and various channels, the atmosphere of language acquisition would be quite relaxing, which will definitely boost students' learning interest, no matter in or after class. In addition, good command of oral and communicative ability would be developed during the learning process. Besides language competence, students' cultural competence would also be improved as their horizon has been broadened, which contributes to better understanding of diversity of cultures all over the world. The cross-cultural communicative ability of students would be strengthened, and students could be better prepared for the possible cross-cultural communication in the workplace or daily life in the future. We should say, microvideo is quite helpful for E-learning, mobile learning and autonomous learning.

\section{Micro-Video Design In College English Teaching: From EMBODIED COGNITION PERSPECTIVE}

The author suggests embodied cognition theory should be applied to college English teaching, so that students, together with teachers, could, better and more effectively, get involved in the teaching activities.

- Students and teachers could label, comment and interact with existed micro-video resources, such as English films, TV programs (TV series, speeches, news reports and even MTV), and Online courses. Accordingly, they would gradually construct open, dynamic, generative, and interactive multimedia instructional resources storehouse catering for their own needs.

- Based on college English courses, and taking students' actual learning ability and language competence into consideration, teachers and students are encouraged to record micro-video resources creatively, concerning topics with high-degree participation or contents which are easily operable in the textbooks, with cameras, mobile phones, and even Adobe Captivate 4 (screen picture recording software), both in and after class. Afterwards having been edited by video editing software, the collected micro-video resources could be applicable as instructional resources for future teaching and study.

- The adapted or self-made micro-video resources would be of great help for students to have open, highly-interactive, and flexible autonomous learning with their mobile terminals, for example, mobile phones, PDA, and MP4. Students are encouraged and resolved to create and practice, using both their mind 
and body. Only in this way could they, with practical experiencing, be motivated to be initiative in study. With the establishment of networked and digital learning pattern in the present information age, their language competence and cognitive ability would be fundamentally enhanced.

- The self-made micro-video resources could be applied into college English teaching, and as a result, the effectiveness of teaching would be promoted. Taking advantage of the deep integration of information technology and instructional design, the design and practice of exploring micro-video as mobile learning resources, available on mobile terminals, bears great significance for promoting informatization and digitization of second language acquisition and teaching of higher education in China. Meanwhile, it provides more evidence for the construction of theories and researches in instructional resources of mobile education aiming to boost digital learning effectiveness.

Besides, the design and practice of exploring micro-video as mobile learning resources, available on mobile terminals, could also provide the great number of front-line teachers of second language acquisition and teaching in China for reference and experience. In addition, it is expected that due attention should be paid by more professionals in micro-class teaching to further discussion and communication concerning this topic.

\section{CONCLUSION}

The paper argues that embodied cognition theory should be integrated with informatization and digitization of second language acquisition and teaching in higher education, which would provide methodological guidance for college English teaching from the embodied cognition perspective. It would, in turn, enrich the research value of embodied cognition theory and application results. Furthermore, it is of great significance for the enhancement of language competence, affective motivation, and cognitive ability of students, together with the development of information technology and professional advancement of teachers in Big Data and digital age.

Teaching process and class activities could be planned and designed in advance, however, they are not presupposited and unable to be operated as computer programs. As a matter of fact, teaching process is self-organized process with the participation of students and teachers, both body and mind; therefore, it, to some extent, brings great challenges to frontline teachers, new teacher in particular, because the participation of both teachers and students must be guaranteed, and the experiencing of specific situation concerning different topics and the establishment of situated knowledge would be quite challenging.

\section{REFERENCES}

[1] M.L. Anderson, Embodied cognition: A field guide. Artificial Intelligence,vol. 149, pp 91-130, 2003.
[2] M. Wilson, "Six views of embodied cognition," J. Psychonomic Bulletin \& Review. Vol. 9 (4), pp 625-636, 2002.

[3] Y.Y. Li and Y.H. Mo, "Educational Significance and Latent Value of Embodied Cognition," J. Journal of Guangxi Teachers Education University: Natural Science Edition. China, vol.28, No.3, pp110-114, September 2011.

[4] J. Wang and W.D. Chen, "Embodied Cognition Theory and Enlightenment to Instructional Design an Technology," J. Journal of Distance Education. China, vol. 210, pp. 88-93, 2012

[5] M. Wang, B. He, and Z.T. "Micro-video Course: Evolution, Position and Application," J. China Educational Technology, vol.4, pp.88-94, 2013

[6] Y. Wang, "The Explanation for the Motivation of Words and Morphology from the Viewpoint of Embodied Philosophy and Cognitive Linguistics," J. Foreign Language Research. China, No.2, pp.1-6, 2004.

[7] X.W. Xu, "Embodied Cognition: An Interdisciplinary Approach to Language Cognition," J. Journal of Guangxi Normal University. Philosophy and Social Science Edition. China, vol.46, pp. 96-101, December 2010.

[8] H.S. Ye, "Embodied Cognition: A New Approach in Cognitive Psychology," J. Advance in Psychological Science. China, vol.18, No. 5, pp.705-710, 2010. 